\title{
Multi-temporal Analysis for Differential Interferometry Synthetic Aperture Radar (D-InSAR) and Its Application to Monitoring Land Surface Displcements
}

\author{
Putu Edi Yastika a*, Norikazu Shimizu b, Tasuku Tanaka c, \\ Takahiro Osawa ${ }^{\mathrm{c}}$ \\ a Graduate School of Environmental Sciences, Udayana University, PB Sudirman Street, Post Graduate Building, \\ Denpasar, Bali 80232, Indonesia \\ ${ }^{b}$ Graduate School of Sciences and Technology for Innovation, Yamaguchi University, 2-16-1 Tokiwadai, Ube, \\ Yamaguchi 755-8611, Japan \\ c Center for Remote Sensing and Ocean Science (CReSOS), Udayana University, PB Sudirman Street, Post Graduate \\ Building, Denpasar, Bali 80232, Indonesia \\ * Correspondence: edi.yastika@gmail.com
}

Received: 23 August 2016; Accepted: 25 January 2017; Available online: 28 January 2017

\begin{abstract}
Land subsidence rate in Semarang has been observed by D-InSAR technique based on ALOSPALSAR data on ascending orbits, which is processed by GMTSAR and ArcGIS software. Two kind of methods namely single D-InSAR and Multi-Temporal D-InSAR has been done. By employing SRTM3 and ASTER1 DEM data to remove the topography component, total 67 pairs of inteferogram has generated. Northeast area and shoreline area has largest subsidence about $20-32 \mathrm{~cm}$ for 4 years or average rate $5-8 \mathrm{~cm} /$ year. Since the northwest area and center area has lower subsidence rate and even no remarkable subsidence occurred, this area seems to be stable comparing the northeast area Removing the topography component phase to get displacement phase from the phase interferogram by using SRTM3 DEM and ASTER1 DEM data respectively, the both results coincided with 0.995 correlation value. The coherence threshold is an important factor to get better accuracy, but if setting the threshold too high, the process of interference will be failed and not be able to obtain the results in a lot of area. The perpendicular baseline and the temporal baseline (time period) is an important factor to determining the coherence threshold. By using many scenes the Multi-Temporal D-InSAR was applied, and by selecting good pairs of the interferograms, accuracy of the results will be improved. The correlation value for GPS data eventually increased from 0.63 to 0.77 .
\end{abstract}

Keywords: ALOS-PALSAR; D-InSAR; GPS; hyperbolic method; land subsidence; multi-temporal method

\section{Introduction}

Interferometric Synthetic Aperture Radar (InSAR) is a powerful technology for observing the Earth surface, especially for mapping the Earth's topography and deformations (Hanssen, 2003). From previous study on InSAR concludes, some factor affected on its accuracy. These factors affected on the coherence of two images, and determination of coherence threshold become the important point. Another factor severely decreasing the accuracy of InSAR is atmospheric disturbance. Many scientist are studied in mitigating on atmospheric effect on InSAR such as, Shimada (2014), Xiao-li (2008), and Wadge (2002). Removing the atmospheric effects especially by ionospheric disturbance needs sophisticated technique and programs and this problems is challenging on improvement of InSAR accuracy.

Although the application of D-InSAR by single pair interferogam has a good result, but when applying to derive the subsidence for long periods, it is will lose their coherence. Time series analysis by using only single inferogram also not possible, because of that in 
this study not only generating for single inteferogram but also Multi-Temporal interferogram. By applying the Multi-Temporal interferogram method the land subsidence behavior of the chosen observation points can be obtained.

The study area is Semarang City Indonesia, this is the main city in Central Java with a dense population which industry activity as a main business. Semarang extremely threatened by land subsidence that make some buildings and infrastructure sinking to the ground. Land subsidence phenomena in Semarang has been observed by many researcher with various method and discipline such as InSAR method (Kuehn et al., 2009, Leveling method (Marfai and King 2005), Gravity method (Sarkowi et al., 2005) and Global Positioning System (GPS) by Geodesy Reseach group of Institute of Technology Bandung ITB (Abidin et al., 2008-present). Monitoring of land subsidence in this area should be continued and the accuracy should be improved especially on D-InSAR technique. This research result compared to Geodesy research group (ITB) results, as a validation of the InSAR result to the GPS result. The objectives of this study are:

1 To obtain the correlation of single D-InSAR and Multi-Temporal D-InSAR to land subsidence comparing to GPS result.

2 To know the effect of different bases of DEM data to remove the topography component in D-InSAR technique.

3 To know the rates and pattern, of the land subsidence in Semarang city.

4 To improve the accuracy of D-InSAR for long period monitoring on land displacement.

\section{Materials and Methods}

\subsection{Outlines of D-In-SAR}

\subsubsection{D-InSAR Processing to Land Deformation Monitoring}

As mentioned before, the main ability of D-InSAR is for land deformation monitoring, there are some strategies has been developed such as Single interferometric pair and near-zero baseline, Single interferometric pair and non-zero baseline, Three interferometric images and no motion and Two image pairs and no motion in one of them (Agustan, 2010). But in general the steps to produce an interferogram is same. When the two raw SAR data are available, some step to create an interferogram and isolate the phase due to surface deformation should be done. Those step namely: Focusing, coregistration, Generation of Synthetic fringes, Generation of synthetic fringes of topographic phase which is requiring external DEM data, subtracting topographic phase from complex interferogram, Differential phase filtering, Unwraping, Deformation generation, and Geocoding.

\subsubsection{Derivation of Land Subsidence from LOS displacement}

Satellites observed the land displacement on range directions, therefore we need the information about subsidence or vertical displacement $(Z)$. The information about land subsidence can be derived from LOS displacement informations as shown in Figure 1. Figure 1 illustrate the satellites with altitude $(\mathrm{H})$ observing one point on the earth at ascending and descending directions with the off nadir angle $(\theta)$ and slant range (R). Earth curvature effect in this assumptions is neglected since the width of observation area is too small comparing to the radius of Earth.

Before this calculation taken out, the image at first normalized by subtracting all pixel value by pixel value of reference point. After that supposed the displacement at horizontal direction is zero or no displacement, vertical displacement then obtained by divided LOS displacement by $\cos \theta$, whereas $\theta$ is incident angle. This calculation expressed as following equation: 

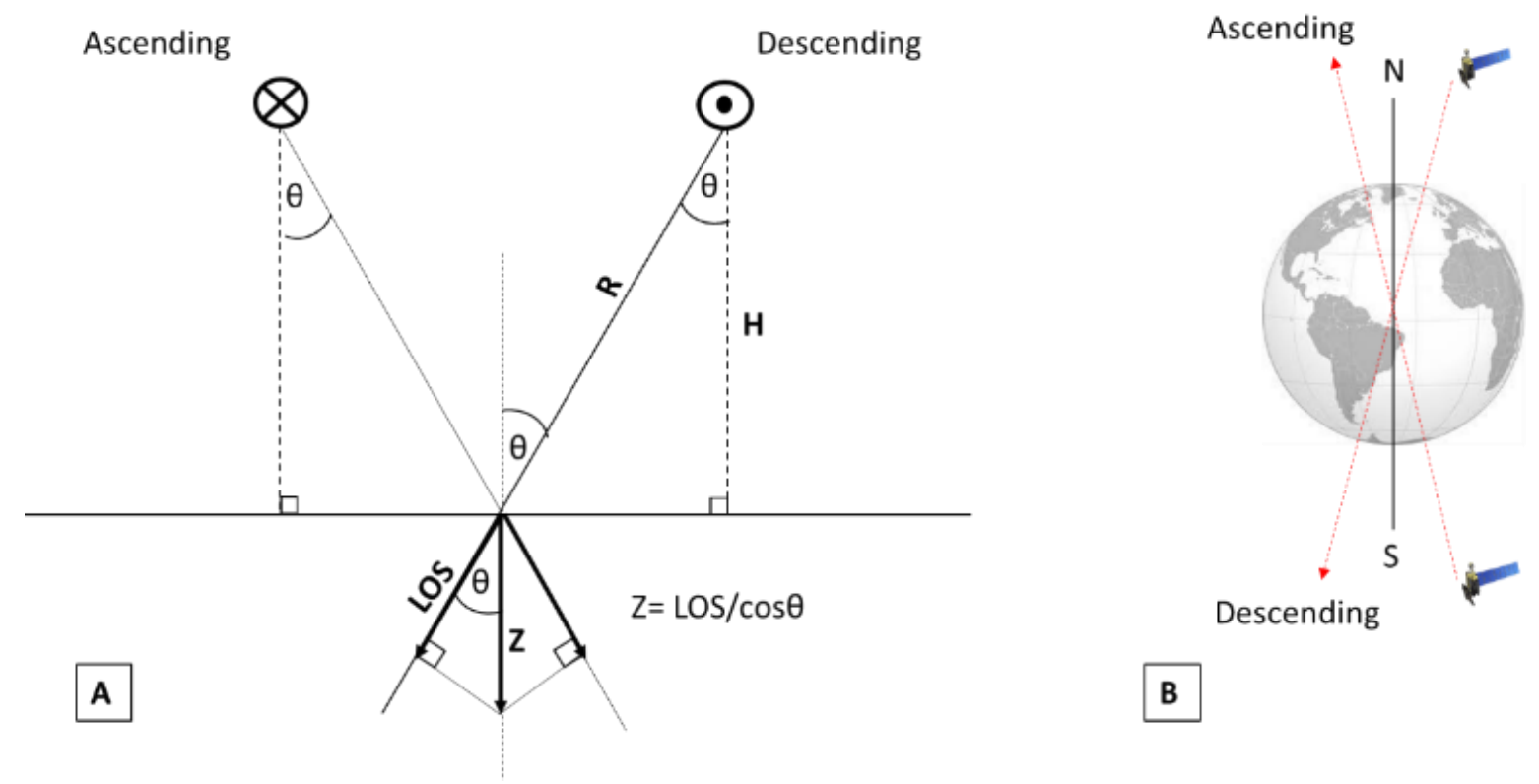

Figure 1. Illustrations of the relation between LOS displacement and subsidence or vertical displacement $(Z)$ observed in ascending and descending orbit (left). Ascending and descending orbit illustrated in Figure B (right)

\subsubsection{D-InSAR Processing, GMTSAR}

Generic Mapping Tools Synthetic Aperture Radar (GMTSAR) is an open source (GNU general Public License) InSAR processing was developed by David Sandwell et al. at Scripps Institution of Oceanography, University of California (Sandwel, et al 2011). The SAR processor code was originally derived from Stanford/JPL FORTRAN and rewritten in the $\mathrm{C}$ programming language ensuring compilation on many platforms using gcc compiler. GMTSAR is command line interface (CLI) software and have ability to process 3 kind of InSAR processing technique they are 2-pass processing, stacking for time series analysis, and ScanSAR to strip-mode. In this study use 2-pass processing which using two SAR images to form an interferogram.

\subsubsection{Land Subsidence Derivation Flowchart}

To get the land subsidence data, some stages should be done. The ALOS-PALSAR and DEM data as input to the GMTSAR to make an interferogram. From GMTSAR line of sight (LOS) displacement obtained in *.grd data format. Los.grd then converted to ESRI data format by GMT to make it readable in ArcGIS. The process then continued using ArcGIS to export that data to TIFF format. Using raster calculator tool in ArcGIS, the LOS displacement data normalized to particular (reference) point. From normalized image the land subsidence then calculated based on eq. (1), and relative displacement obtained. Land subsidence images then extracted to get the subsidence data of determined point or location and continuing in Ms.excel for analysis. The work flow and steps for this task is simply displayed in Figure 2.

\subsection{Aplication of D-InSAR to Land Subsidence Monitoring}

\subsubsection{Studi Area}

Study area is Semarang city located on the north of Java Island. Geographically Semarang city lies on $6^{\circ} 58^{\prime} \mathrm{S} 110^{\circ} 25^{\prime} \mathrm{E}$. With an area of 373.70 square kilometers $(144.29$ sq $\mathrm{mi}$ ) and a population of approximately 2 million people it is the capital and largest city of the Central Java province. Figure 3 shown the location of Semarang City. Semarang extremely threatened by land subsidence that make some buildings and infrastructure sinking to the ground. The monitoring of land subsidence in Semarang should be continued to update the displacement trend information. 


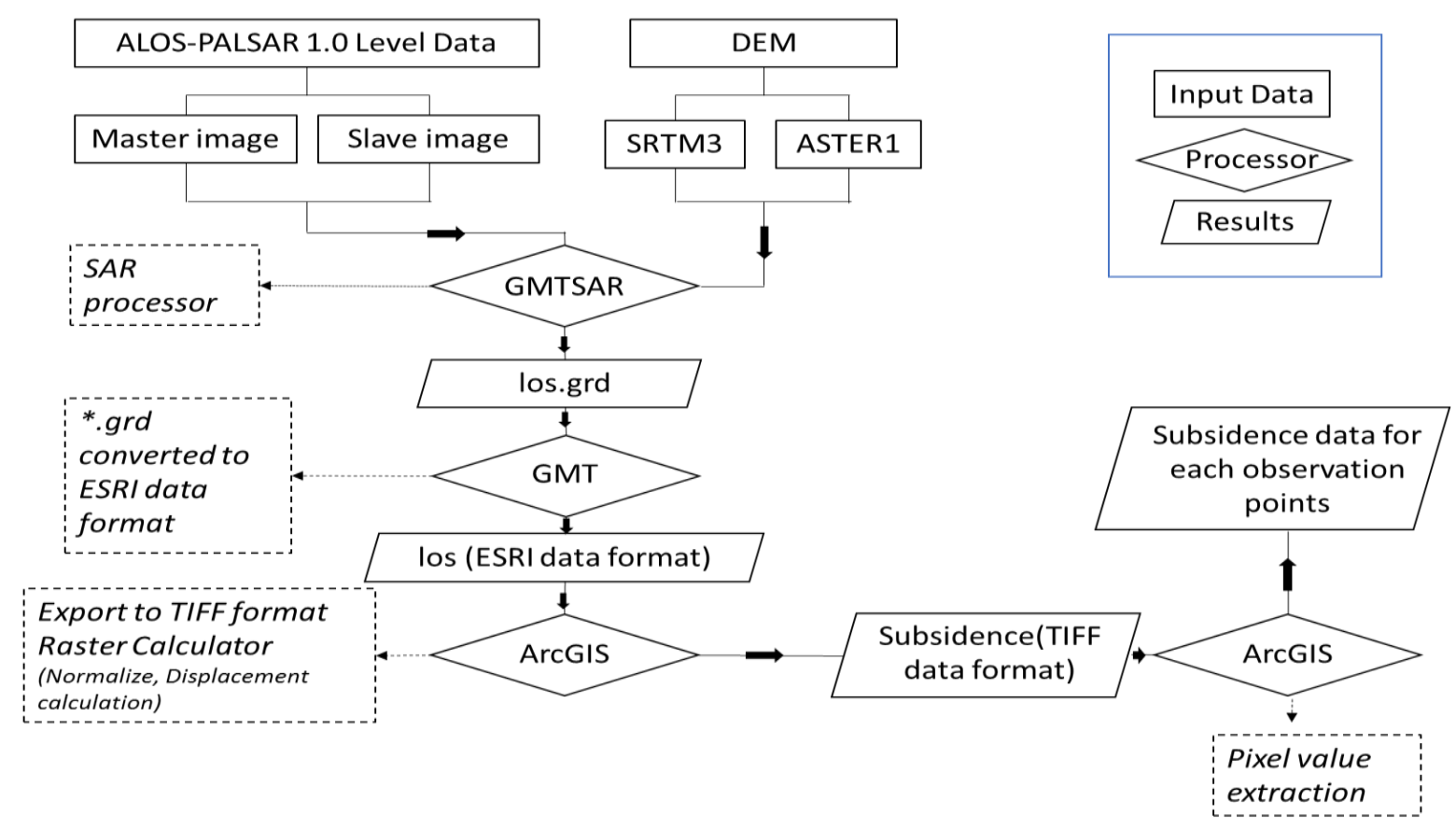

Figure 2. Land subsidence derivation flowchart in D-InSAR technique

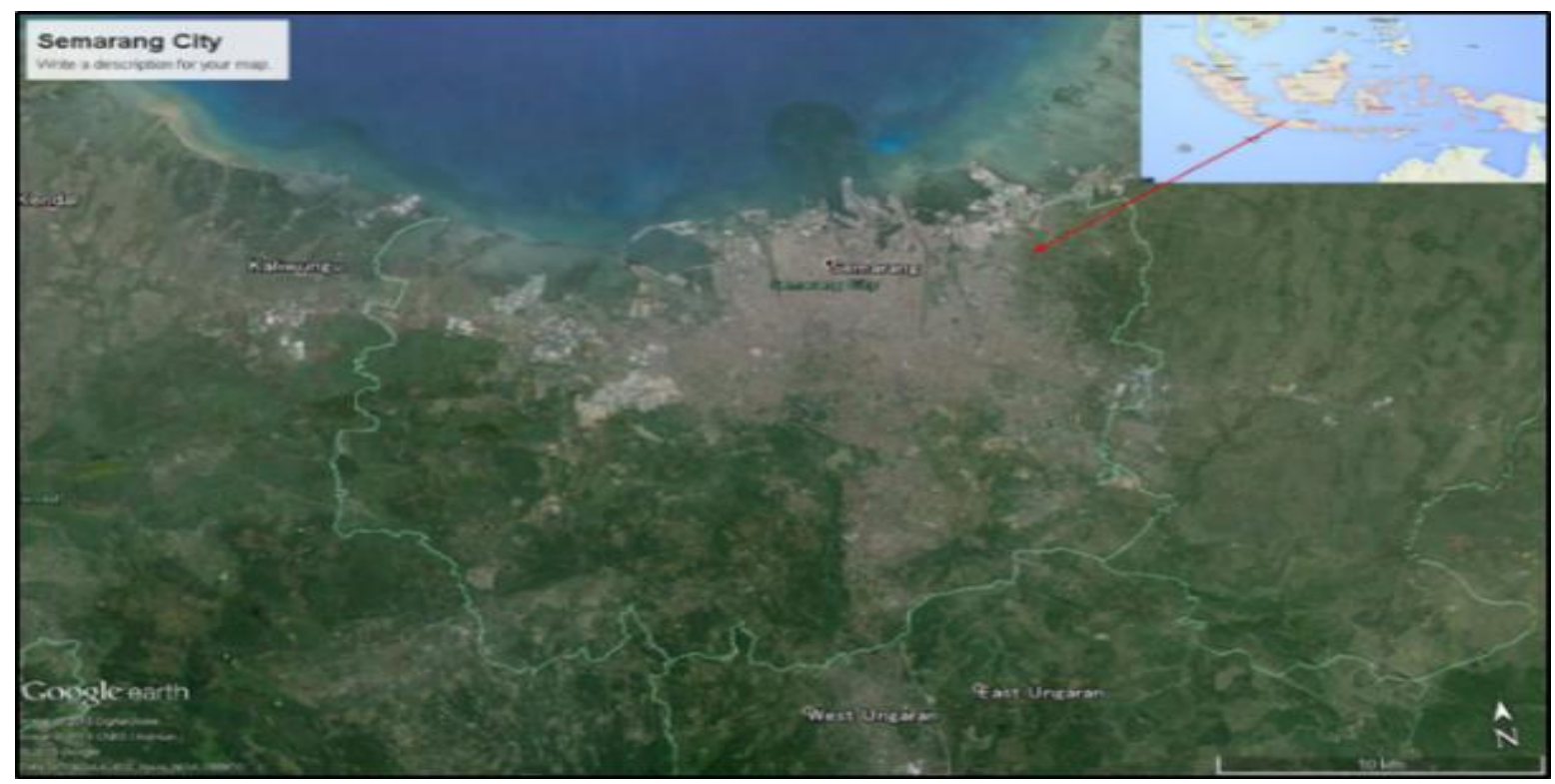

Figure 3. Semarang city location on map (Google earth image, 2015)

\subsubsection{Data Collections}

In this study use 2 type of data classified as primary data and secondary data. Primary data is including SAR images and DEM data, while secondary data is subsidence data derived by GPS.

For land subsidence monitoring by D-InSAR in this study 31 scenes of ALOS-PALSAR level 1.0 data was used. Those data consists of 23 scenes on ascending orbit observation. All of the data provided by Japan Exploration Agency (JAXA). For the ascending scenes names, Fine Beam Single (FBS) mode data marked by "S" and "D" for Fine Beam Dual (FBD) mode respectively. This names is not standard, only for simplifier to give the names when identify for interferogram pairs. Table 1 showing the time table of all data acquisition date.

To remove the phase component of topography, 2 types of DEM was used namely Shuttle Radar Topography Mission3 (SRTM3) data and Advanced Space-borne Thermal 
Emission and Reflection Radiometer (ASTER) Global Digital Elevation model Data. All of these DEM data is free and downloaded from http://topex.ucsd.edu/gmtsar/demgen/. DEM data must be larger than SAR image area or cover whole of SAR area.

Table 1. Data acquisition date of ALOS/PALSAR and GPS

\begin{tabular}{|c|c|c|c|c|c|c|c|c|c|c|c|c|}
\hline No & 1 & 2 & 3 & 4 & 5 & 6 & 7 & 8 & 9 & 10 & 11 & 12 \\
\hline $\begin{array}{l}\text { Month } \\
\text { Year }\end{array}$ & Jan & Feb & Mar & Apr & May & Jun & Jul & Aug & Sep & Oct & Nov & Dec \\
\hline 2007 & So & & & & & D1 & & & D2 & S1 & & S2 \\
\hline 2008 & S3 & & S4 & D3 & & D4 & $\begin{array}{c}\text { D5 } \\
\text { GPS }\end{array}$ & & D6 & S5 & & S6 \\
\hline 2009 & S7 & & & & & $\begin{array}{c}\text { D7 } \\
\text { GPS }\end{array}$ & & & & S8 & & S9 \\
\hline 2010 & S10 & & S11 & & & D8 & GPS & & D9 & & D10 & S12 \\
\hline 2011 & & & & & & GPS & & & & & & \\
\hline \multicolumn{3}{|c|}{ Bar color Legend } & \multicolumn{2}{|c|}{ OBS Path } & \multicolumn{2}{|c|}{$\begin{array}{l}\text { Frame } \\
\text { center }\end{array}$} & \multicolumn{3}{|c|}{ Operation mode } & \multicolumn{3}{|c|}{ Orbit Direction } \\
\hline \multicolumn{3}{|c|}{$\begin{array}{c}\mathrm{S}=\text { Single Beam } \\
\text { Ascending }\end{array}$} & \multicolumn{2}{|c|}{431} & \multicolumn{2}{|c|}{7040} & \multicolumn{3}{|c|}{ FBS } & \multicolumn{3}{|c|}{ Ascending } \\
\hline \multicolumn{3}{|c|}{$\begin{array}{c}\mathrm{D}=\text { Double Beam } \\
\text { Ascending }\end{array}$} & \multicolumn{2}{|c|}{431} & \multicolumn{2}{|c|}{7040} & \multicolumn{3}{|c|}{ FBD } & \multicolumn{3}{|c|}{ Ascending } \\
\hline \multicolumn{3}{|c|}{ GPS Data } & \multicolumn{10}{|c|}{ Data collection period with GPS (ITB data) (Abidin, et al) } \\
\hline
\end{tabular}

For Secondary data using the subsidence data derived by GPS.This secondary data is used as a comparison for subsidence data obtained from the D-InSAR. This secondary data was provided by Geodesy Research Group, Institute of Technology Bandung (ITB) whose has been monitoring for land subsidence in Semarang city since July 2008. 44 GPS stations has determined and GPS static survey method has been employing.

\subsubsection{Pair Selection to Generate D-InSAR}

\section{a. Selection for Single D-InSAR}

Single D-InSAR is observation of displacement during two dates by employing one interferogram, that is means the beginning of observation set as a master and end of observations set as slave. In this study, 2 pairs of single D-InSAR has generated that is D5D7 and D7D8 to derive the land subsidence during July 2008-June 2009 and June 2009-June 2010 respectively. This date chosen to match with data acquisition date by GPS. ASTER1 DEM data also use to remove the topography phase and compare to the result of interferogram that removed by using SRTM3 DEM. Comparison is needed to evaluate the effect of different DEM data on the displacement results.
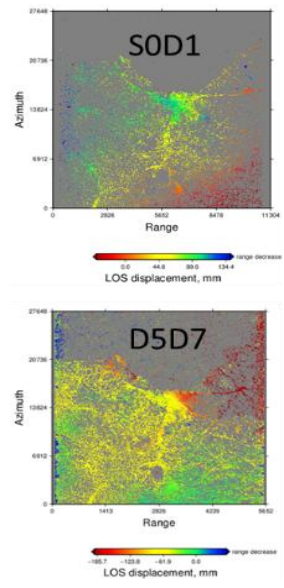
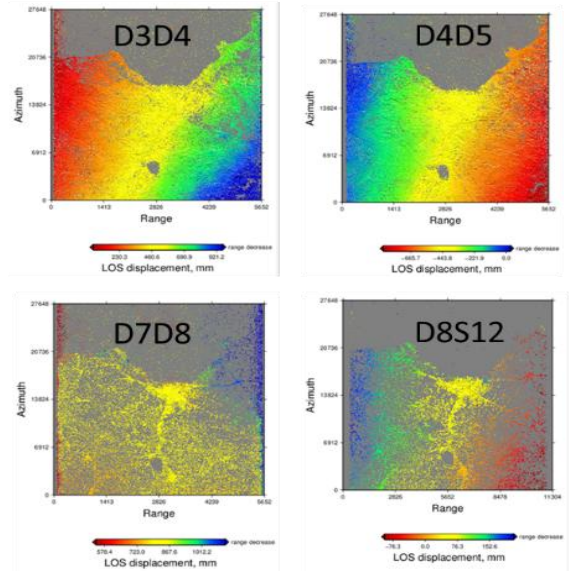
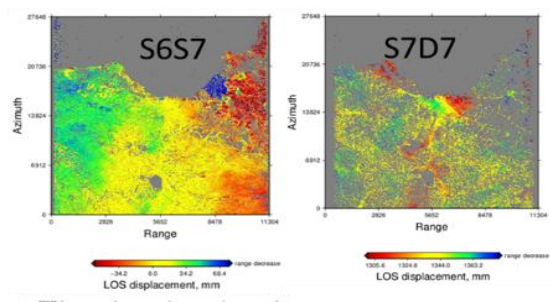

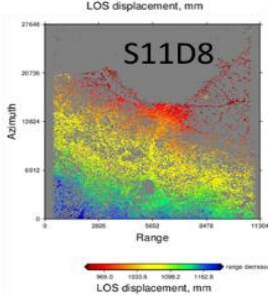

Figure 4. An Example of LOS displacemet image 


\section{b. Selection for Multi-Temporal In-SAR}

Multi-Temporal D-InSAR is observation of displacement during two dates by employing all acquired data during the period of that two dates. The displacement has derived by each pair then accumulated to get total displacement. To derive total displacement by multi temporal D-InSAR, in this study employing 22 pairs. ASTER 1 DEM also has used to remove the topography component in this 22 pairs beside SRTM3 DEM.

To comparing with GPS data, total displacement during July 2008-June 2009 derived by adding D5D6, D6S5, S5S6, S6S7 and S7D7. While to derive the displacement during June 2009-June 2010, got by adding pair D7S8, S8S9, S9S10, S10S11 and S11D8.

c. Selecting Pair of Interferogram to Avoid Ionospheric and Orbital Error on MultiTemporal D-InSAR

Multi-Temporal interferogram employing all the data acquisition during of two dates. Because of large amount of data, some of them perhaps has large error causing by atmospheric delay or orbital error. The interferogram phase image which contain big error will showing particular pattern depend on error sources. When this such image identified has such as pattern visually, this pair will be terminated and replaced by another pair in displacement calculation.

\section{Results}

All pairs both of ascending and descending direction data has been processed, the coherence, phase interferogram, phase filtering, phase masking, phase unwraping and geocoding has been done by using GMTSAR. Figure 4 shows some example of LOS displacement images obtained by GMTSAR.

\subsection{Subsidence Rates for Each Observation Point Derived by Single D-InSAR and Muilti- Temporal D-InSAR}

From 44 points has extracted, 10 points lost its data because the coherence value in that point below the threshold (0.13). This result presented on Figure 5 of subsidence during 2008-2009 and subsidence during 2009-2010 respectively which observed by GPS and D-InSAR.
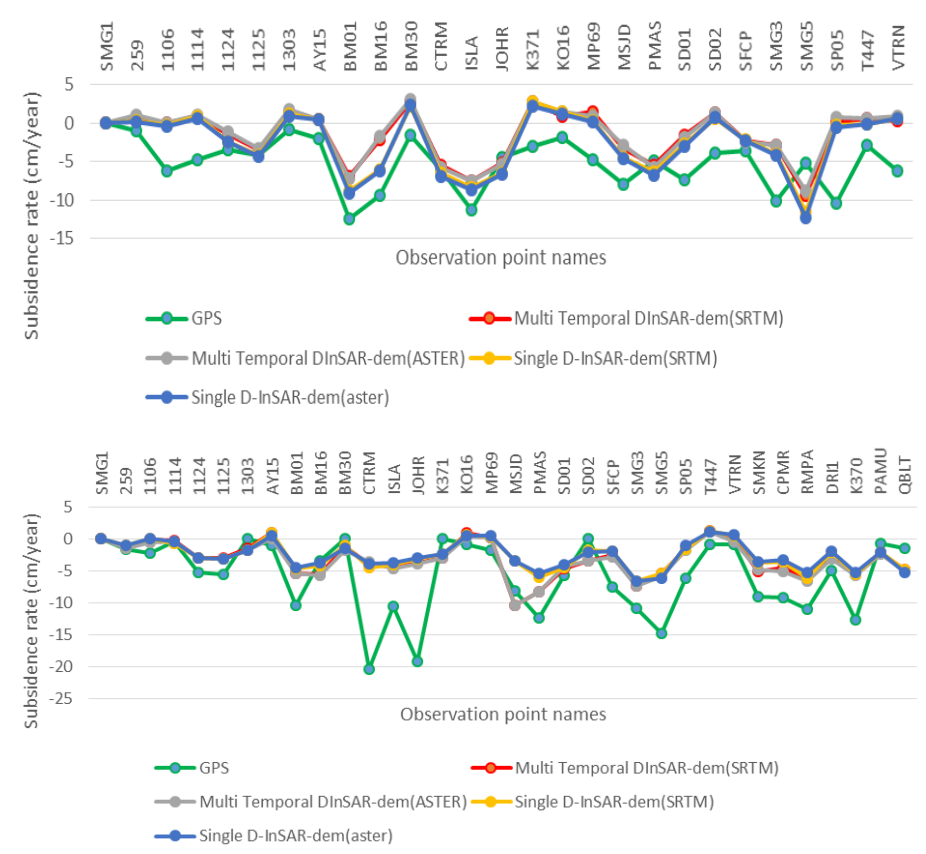

Figure 5. Subsidence rate for 2008-2009 (top) and for 2009-2010 (bottom) 


\subsubsection{Comparison of Single and Multi-Temporal D-InSAR Result with GPS Data}

To know the accuracy of D-InSAR, its result then compared to GPS result by using linear correlation. By setting the coherence threshold value on 0.13 , only 34 points of 44 points give the result. These correlation graphic presented in Figure 6 which is showing the correlations GPS and Single and Multi-Temporal D-InSAR, which topography component removed by SRTM3 and ASTER 1 for subsidence during 2009-2010 respectively.

Figure 6 seen the single D-InSAR has a bigger correlation to GPS data instead of multi temporal D-InSAR in thiscase. Comparing to GPS data single D-InSAR has root mean squared error (RMSE) $4.27 \mathrm{~cm}$ for observation during 2008-2009 and $5.47 \mathrm{~cm}$ for 20092010 respectively. On the other hand RMSE value of Multi-Temporal D-InSAR is $4.57 \mathrm{~cm}$ for observation during 2008-2009 and $5.21 \mathrm{~cm}$ for 2009-2010 respectively.
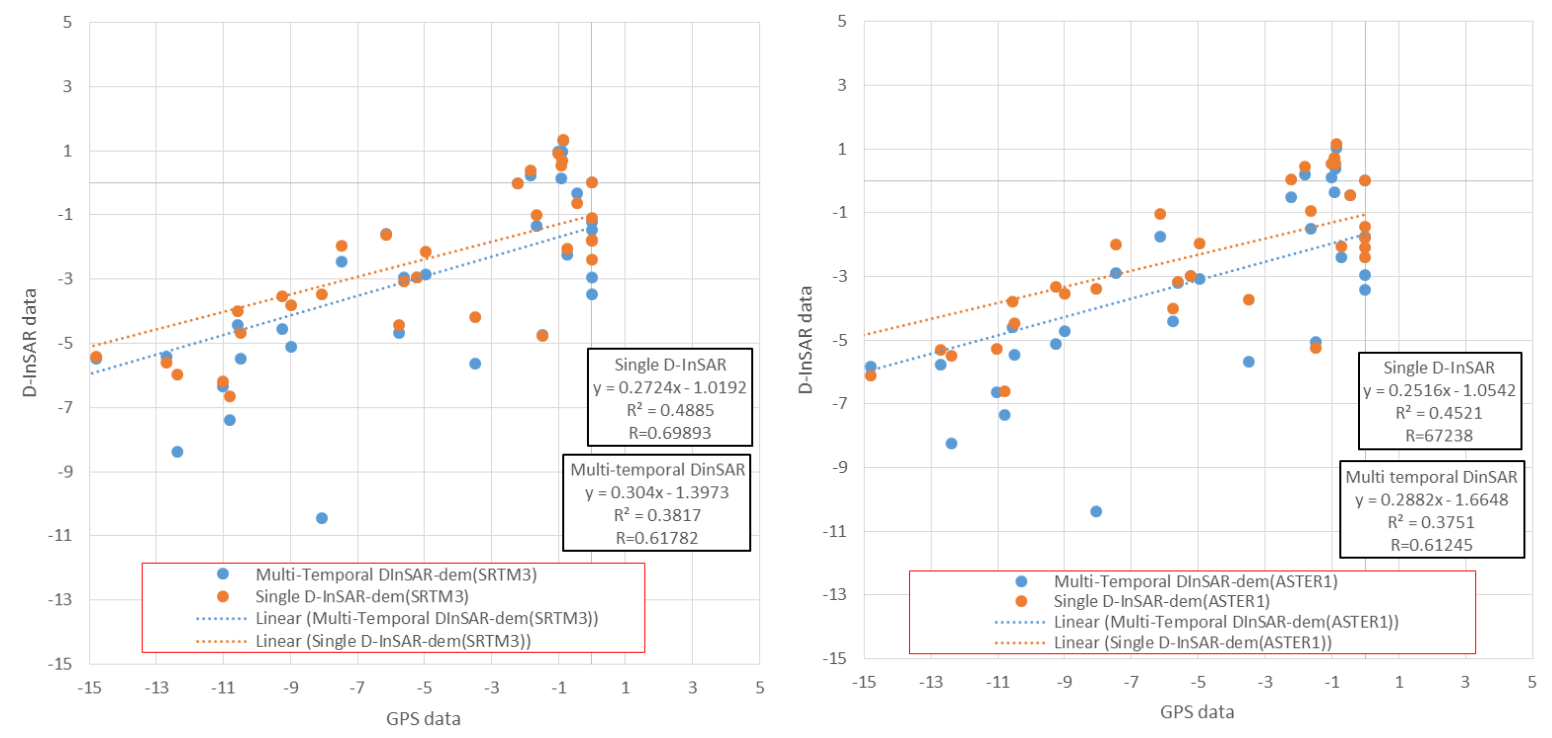

Figure 6. Correlation GPS with Multi temporal D-InSAR and Single D-InSAR topography removed by DEM SRTM3 (left) and DEM ASTER1 (right), respectively

\subsubsection{SRTM3 DEM and ASTER1 DEM Issues}

Figure 6 shows the results by employing SRTM3 DEM to remove topography phase looks has a slightly bigger correlation to GPS data comparing to result which employing ASTER1, almost in all case. To check the deference of the displacement results by utilizing two different DEM (SRTM3 and ASTER1), the graphic of correlations also made and 0.9979 correlation value has obtained.

For Alos-Palsar that utilizing L-Band it is possible to create an interferogram with longer baseline than other satellites that utilizing shorter wavelength. With the shorter perpendicular baseline $(<500 \mathrm{~m})$ and topography phase removed by using DEM with error 7-10 $\mathrm{m}$, the phase change causing by DEM error only a few mm (GSI, 2004).

\subsubsection{Subsidence Rate in Time Series Analysis}

Although subsidence rate derived by Multi-Temporal D-InSAR has worse correlation than single D-InSAR comparing to GPS data, but Multi-Temporal D-InSAR providing the time series analysis which that is impossible in single D-InSAR. In this section showing the behavior of subsidence rate of each observation point for 4 years, during January 2007 until December 2010. This result obtained by extraction of multi temporal D-InSAR which topography component removed using SRTM3-DEM data. Figure 9 shows the subsidence pattern of each points. From that's Figure we can see there are three major pattern of subsidence which marked by circle with different color. 


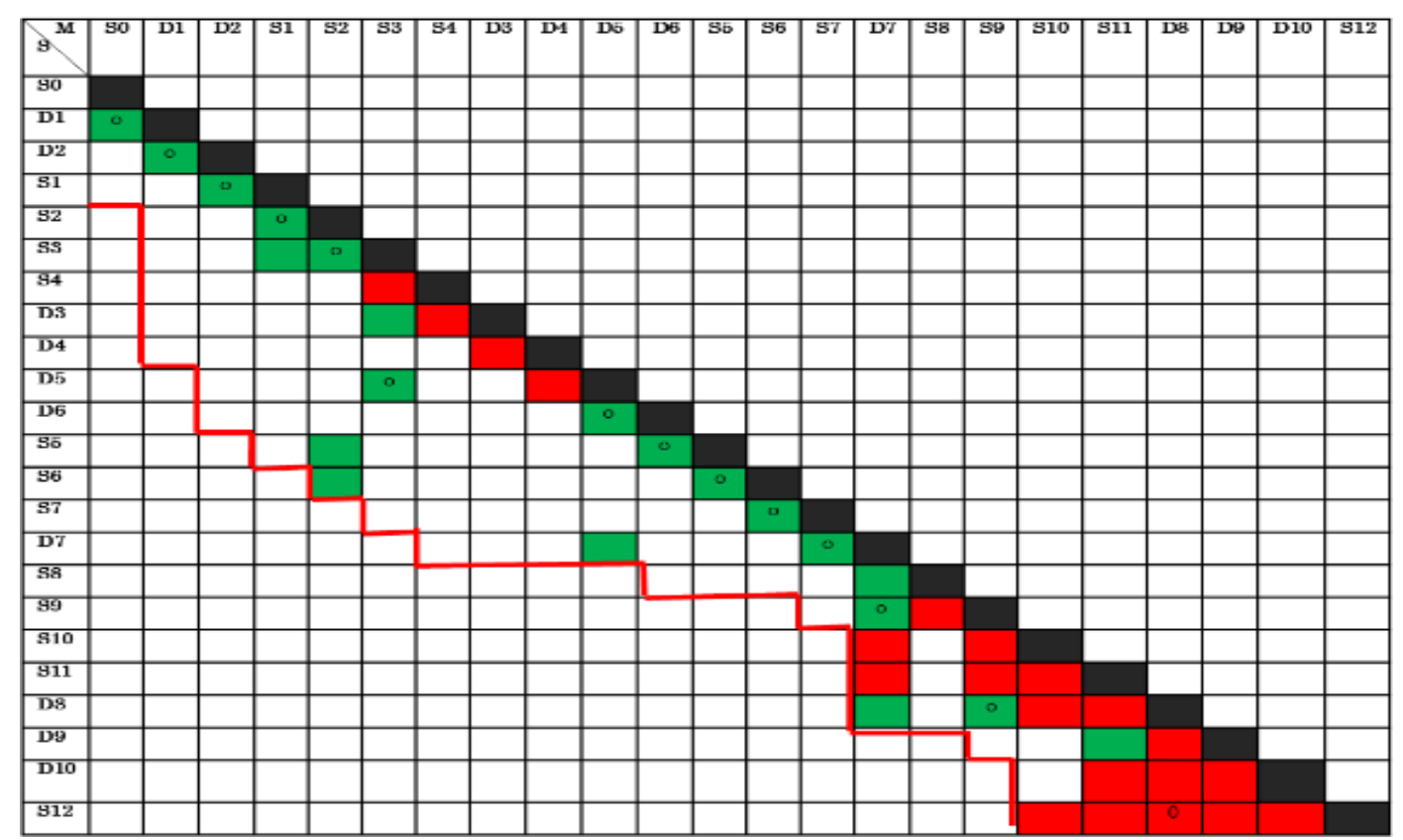

Figure 7. Phase interferograms pair state, red block represent the tinterferogram suspected disturbed by major errors, while the green block represent the fairly less of errors

\subsubsection{Correction of Multi-Temporal D-InSAR from Ionospheric Error and Orbital Error}

Satellite synthetic aperture radar (SAR) signals are often seriously disturbed by atmospheric delays. Some of the phase interferogram shows the parallel fringe, non-linear and strange pattern. The parallel fringe suspected caused by orbital error and non-linear and strange pattern corresponding to ionospheric error. These fringes make the interpreting the final surface deformation results becomes difficult (Shimada, 2014).

Until now there is no standard method or programs to remove the ionospheric error on InSAR interferogram. The easy way to avoiding these error is avoid suspected image from calculation. The pairs that indicated dominated by error will be cancel out from the displacement calculation. The condition of each pair is presented in Figure 7.

The Red block in Figure 7 means that pairs has parallel and strange pattern where indicating this interferogram dominated by ionospheric error and/or orbital error. These interferogram expressed as bad interferogram. While the green block indicating the interferogram has a less or safe from orbital error and/or ionospheric error. The pairs bellow red line indicating has a time span between the master and slave more than 1 year.

By excluding the bad interferogram, the combination of the Multi Temporal D-InSAR will be change, the amount of pairs used also decrease only 14 pairs is used. To derive the land deformation from January 2007 to December 2010 the pairs use is S0D1, D1D2, D2S1, S1S2, S2S3, S3D5, D5D6, D6S5, S5S6, S6S7, S7D7, D7S9, S9D8 and D8S12. Pair D8S12 still included to the calculation even it is indicated as a bad interferogram since, all of interferograms involving S12 scene gave the bad results. After correction seen some point become close to GPS observation, this means the results and that point has improved. To check its improvement on the results, the correlation to GPS data and calculation for RSME value also made as shown in Figure 8.

A shown in Figure 8 we got the correlation value of GPS and Multi Temporal D-InSAR increased after the bad pair cancel out from calculation. RMSE value of corrected Multi temporal D-InSAR to GPS data also smaller that is $4.456 \mathrm{~cm}$ instead of before correction $5.208 \mathrm{~cm}$. These result shows that, by remove the bad pair from combination can improve the Multi-Temporal D-InSAR results.

The subsidence pattern of some points for 4 years shows in Figure 9. There are three major pattern that marked by different color circle. North east area seem has a largest subsidence comparing to another area. 


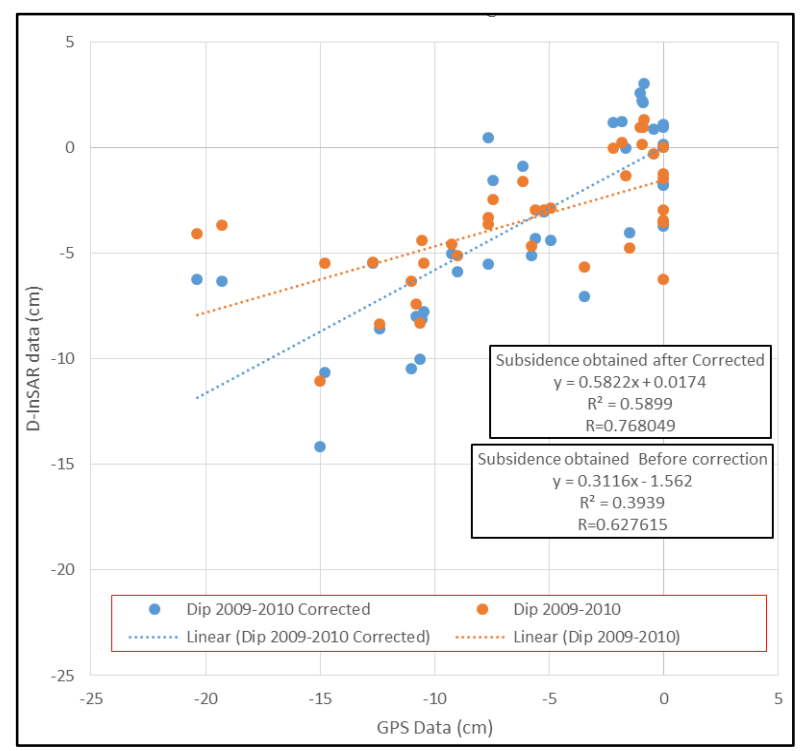

Figure 8. Correlation of subsidence data derived by GPS and Multi-temporal D-InSAR after and before correlation of pair combination for observation during 2009-2010

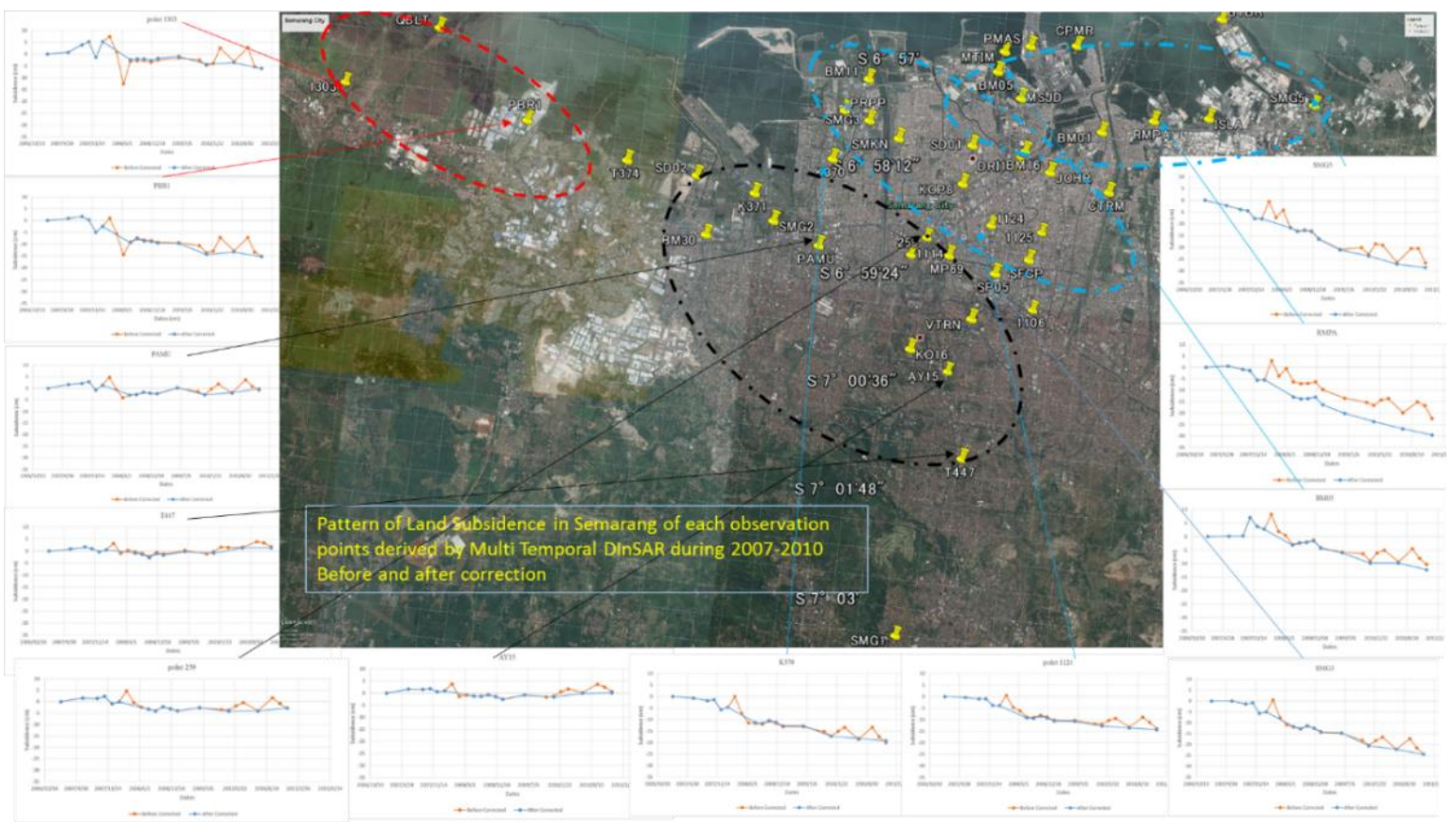

Figure 9. The subsidence pattern of some observation points on Semarang for 4 years derived by Multi-Temporal D-InSAR before correlation (orange lines) and after correlation (blue lines)

\subsection{Map of Subsidence Rate of Semarang City}

By using ArcGIS software, the map of Subsidence rate can be made based on MultiTemporal D-InSAR results. Figure 10 showing the map of subsidence rate for 4 years derived by using Multi-Temporal D-InSAR which the topography phase removed by using SRTM3-DEM. Northeast area and shoreline area seem has largest subsidence range 200$320 \mathrm{~mm}$ for 4 years or average rate $50-80 \mathrm{~mm} /$ year, represent as yellow to dark orange color on the map. At the northwest area subsidence observed at lower rate about 20-80 $\mathrm{mm}$ for 4 years or $5-20 \mathrm{~mm} /$ year represented as blue until green color on the map. Dark purple color mixing with light purple color mainly seen in center part of Semarang, that means in this area there is no subsidence or slightly uplifted relative to reference point. 


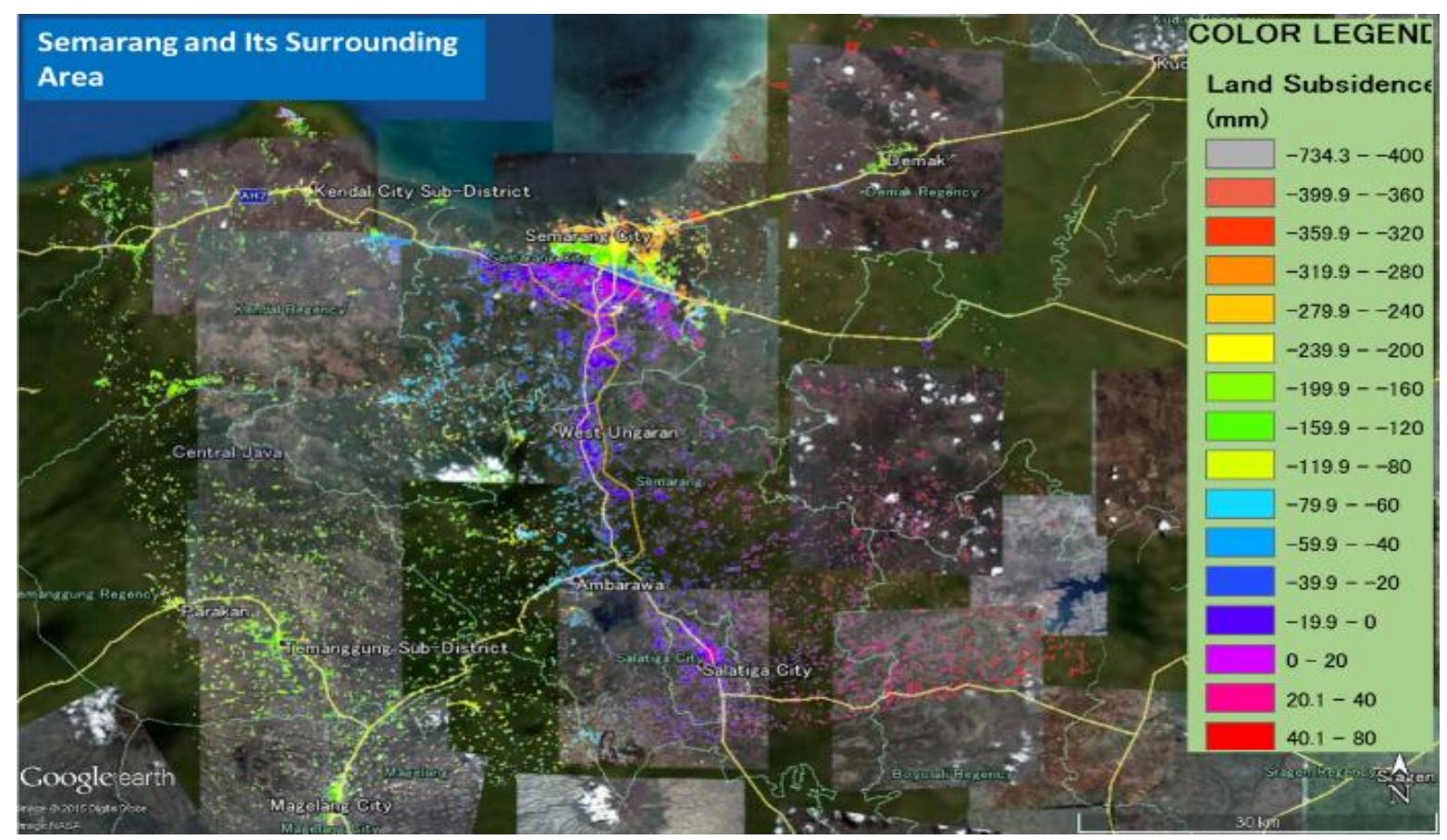

Figure 10. Land subsidence in Semarang during January 2007 to Dec 2010 derived by ALOS-PALSAR data using Multi-Temporal D-InSAR methods, superimposed on the Google Earth image that was taken on March 2007

\section{Conclusions}

Land subsidence rate in Semarang has been observed by D-InSAR technique based on ALOS-PALSAR data on ascending orbits, which is processed by GMTSAR and ArcGIS software. Two kind of strategy namely single D-InSAR and Multi-Temporal D-InSAR has been done. By employing SRTM3 and ASTER1 DEM data to remove the topography component, total 67 pairs of inteferogram has generated. The land displacement of targeted points then extracted and as the result, the following points were noticed:

1. Both of Single and Multi-Temporal D-InSAR has merit and demerit. Correlated to GPS result for measuring the land displacement on short period, single D-InSAR has better correlation than Multi-Temporal D-InSAR but Single D-InSAR will lose its coherence for long periods monitoring. Using Multi-Temporal D-InSAR, time series analysis can be carried out which is not possible in single D-InSAR.

2. With the small baseline perpendicular, few meter altitude measurement error on DEM that used to remove the topography phase still considerable. Removing topography phase to get displacement phase on phase interferogram, by using SRTM3 DEM or ASTER1 DEM data will got similar results. These proofed by 0.995 correlation value between the results of SRTM3 and ASTER1.

3. Northeast area and shoreline area has largest subsided about $20-32 \mathrm{~cm}$ for 4 years or average rate $5-8 \mathrm{~cm} /$ year. Northwest and center are has a lower subsidence rate and even no subsidence occurred, this area seem has a better stability comparing than northeast area.

4. By using many scenes it is possible to generate the multi temporal D-InSAR, and selection on good pairs only, will improve its accuracy.

\section{Acknowledgments}

All of ALOS-PALSAR and ASTER1 data was used in this research provided by Japan Space Exploration Agency (JAXA) based on cooperation between Yamaguchi University, Cresos Udayana and JAXA. SRTM3 DEM data provided by JPL/NASA and GPS data in Semarang provided by Geodesy group of ITB (Institute of Technology Bandung). Many thanks to those all parties whose support for the data on this research. DInSARprocessed by using GMTSAR software which developed by David T. Sandwell, et al. 
many thanks also for them. I am further indebted to Prof. Masanobu Shimada for numerous discussions and advice during this study and also to Indonesian goverment for the scholarship trough Beasiswa Unggulan.

\section{References}

Abidin, H. Z., Andreas, H., Gumilar, I., Sidiq, T. P., \& Fukuda, Y. (2013). Land subsidence in coastal city of Semarang (Indonesia): characteristics, impacts and causes. Geomatics, Natural Hazards and Risk, 4(3), 226-240.

Agustan. (2010). Ground deformation detection based on ALOS-PALSAR data utilizing DInSAR technique in Indonesia. (PhD Dissertation). Nagoya-Japan: Graduate School of Environmental Studies, Nagoya University .

Hanssen, R. F. (2003). Subsidence monitoring using contiguous and PS-InSAR: Quality assessment based on precision and reliability. Proceedings 11th FIG Symposium on Deformation Measurements. Santorini, Grace.

Kuehn, F., Albiol, D., Cooksley, G., Duro, J., Granda, J., Haas, S., Hoffmann-Rothe, A., \& Murdohardono, D. (2010). Detection of land subsidence in Semarang, Indonesia, using stable points network (SPN) technique. Environmental Earth Sciences, 60(5), 909-921.

Sandwell, D., Mellors, R., Tong, X., Wei, M., \& Wessel, P. (2011). GMTSAR: An InSAR processing system based on generic mapping tools. Scripps Institution of Oceanography. [online]. Available at: http://topex.ucsd.edu/gmtsar/tar/GMTSAR.pdf.

(C) 2017 by the authors; licensee Udayana University, Indonesia. This article is an open access article distributed under the terms and conditions of the Creative Commons Attribution (CC-BY) license (http://creativecommons.org/licenses/by/4.0/). 